\title{
Understanding forage grass genomes beyond single nucleotide variation - an example on self- incompatibility
}

\section{Conference Paper}

Author(s):

Studer, Bruno; Rohner, Marius; Manzanares, Chloe; International Lolium-Festuca Pangenome Consortium

Publication date:

2021

Permanent link:

https://doi.org/10.3929/ethz-b-000528455

Rights / license:

In Copyright - Non-Commercial Use Permitted

Originally published in:

https://doi.org/10.5507/vup.21.24459677.11 


\title{
Understanding forage grass genomes beyond single nucleotide variation - an example on self-incompatibility
}

\author{
Bruno Studer ${ }^{1[0000-0001-8795-0719]}$, Marius Rohner ${ }^{1}$, \\ Chloé Manzanares ${ }^{1}$ and the International Lolium-Festuca \\ Pangenome Consortium ${ }^{2}$
}

\author{
${ }^{1}$ Molecular Plant Breeding, Institute of Agricultural Sciences, ETH Zurich, \\ Universitaetstrasse 2, 8092 Zurich, Switzerland \\ ${ }^{2}$ The International Lolium-Festuca Pangenome Consortium (ILFPC), including the following \\ authors and affiliations: \\ Teagasc, Ireland, represented by Stephen Byrne \\ LAMMC, Lithuania, represented by Gintaras Brazauskas \\ DLF Seeds A/S, Denmark, represented by Christian Sig Jensen \\ LfL, Germany, represented by Stephan Hartmann \\ AgResearch, New Zealand, represented by Jeanne Jacobs \\ Norwegian University of Life Sciences, Norway, represented by Odd Arne Rognli \\ Agroscope, Switzerland, represented by Christoph Grieder \\ Aarhus University, Denmark, represented by Torben Asp \\ ETH Zurich, Switzerland, represented by Bruno Studer
}

\begin{abstract}
The genera Lolium and Festuca comprise the most important forage and turf grass species of temperate regions worldwide. Despite tremendous advancements in DNA sequencing technologies and genome assembly methods, genome sequences of highest quality in terms of completeness, correctness and contiguity are yet to be established for the Lolium-Festuca species complex. The International Lolium-Festuca Pangenome Consortium (ILFPC) has set out to fill this gap and aims at establishing multiple high-quality genome sequences to advance forage and turf grass research and breeding.

Here we report about first results of the joint efforts within ILFPC and, more importantly, how the established genomic resources can help answering biological questions. Using self-incompatibility (SI) as an example, we present how whole genome assemblies can be used to resolve the gene content and order at one SI locus, previously identified by fine-mapping. The multiple genomes obtained through ILFPC also enabled us to compare the gene constitution of different genotypes within and across species and link this information to SI functionality.

The availability of multiple high-quality genome assemblies constitutes a milestone for genetic studies, functional biology and genomics-assisted breeding. Moreover, comparing genomes and moving towards pangenomics opens new opportunities to describe structural genome variation and unlock genetic diversity in the LoliumFestuca species complex.
\end{abstract}


Keywords: Lolium-Festuca species complex, International Lolium-Festuca Pangenome Consortium (ILFPC), Self-incompatibility.

\section{Introduction}

More than a century ago, Charles Darwin recognised the inability of plants to reproduce by self-pollination, a phenomenon known as self-incompatibility (SI). Since then, we have learned much about the genetic control of different SI systems that have evolved independently in different plant families. In the grass family (Poaceae), which is one of the largest plant families containing representatives of major forage and turf grass species, the SI mechanism remains elusive. Poaceae SI, unlike other systems, is governed by at least two multi-allelic, independent loci, $S$ and $Z$. Map-based cloning of the S-locus in perennial ryegrass (Lolium perenne L.) identified the pollen component involved in the initial recognition during the SI reaction, a gene belonging to the DUF247 protein domain-containing gene family (hereinafter referred to as LpSDUF247) [1]. Similar to $S$, two independent mapping populations with more than $10^{4}$ individuals segregating for $Z$ were used to pinpoint the $Z$ locus to a single BAC clone, containing five positional candidate genes (manuscript in preparation). However, none of the genes identified at $Z$ have been unequivocally assigned to SI. The aim of this study was to further validate the $Z$ locus region, by comparing the haplotypes of several genotypes of the Lolium-Festuca species complex.

\section{Material and Methods}

The perennial ryegrass haplotype containing the $Z$ locus (BAC clone P205) was compared with the orthologous genome region from Byrne et al [2] (P226) and the doubled haploid perennial ryegrass genotype Kyuss [3]. Whole genome assemblies of a L. multiflorum Lam., Festulolium and Festuca pratensis Huds. genotype were established within ILFPC following the method described by Copetti et al. [4]. Genome sequences of Dactylis glomerata L. were taken from Huang et al. [5]. For synteny map construction, the gene models from Kyuss and L. multiflorum Lam. were used to identify the orthologous gene sequences. The presence and position of a specific gene in each contig, scaffold, or pseudomolecule were stored as coordinates in a CMAP format. The SimpleSynteny platform [6] was used to process each CMAP file individually and to illustrate a synteny map between the different genotypes and species. 


\section{Results and Discussion}

The genomic constitution of the $Z$ locus region previously established for perennial ryegrass (BAC clone P205) was confirmed in other genotypes of the LoliumFestuca species complex (Figure 1). Gene content and order were conserved within genotypes exhibiting a functional SI system. A gene encoding for a protein containing a "domain of unknown function 247 " is present in duplicate within the $Z$ locus (LpZDUF247A and LpZDUF247B). Like for LpSDUF247 at the $S$ locus, the $L p Z D U F 247 A$ and $L p Z D U F 247 B$ genes were highly diverse between perennial ryegrass genotypes but also across the different Poeae species. In combination with flanking markers from fine-mapping, they constitute prime candidates for involvement in initial pollen-stigma recognition of a functional SI response. A continuous and complete haplotype reconstruction as well as haplotype-based diversity measurements were only possible with the assembled high-quality genome sequences obtained through ILFPC. In Manzanares et al. [1], despite the same initial fine-mapping and BAC clone sequencing approach, the $S$ locus region was not complete, hindering the discovery of the female $S$ component.
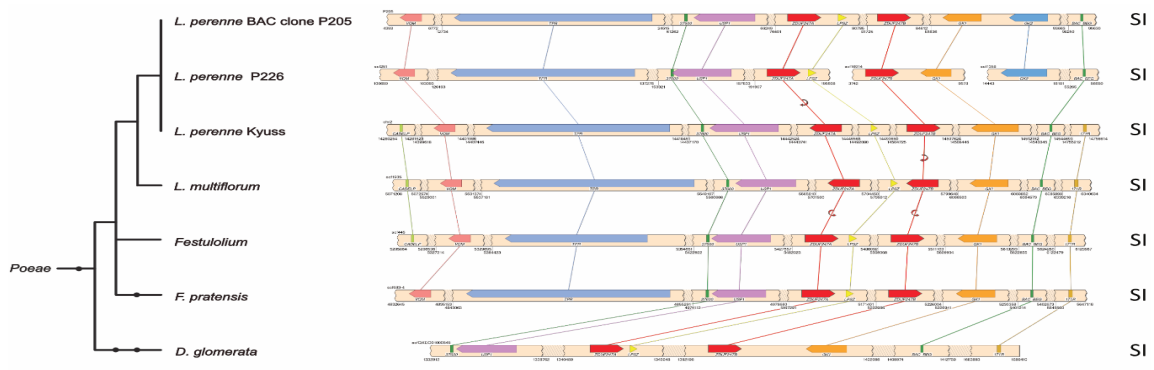

Fig. 1. Synteny map of the $Z$ locus between multiple self-incompatible perennial ryegrass genotypes and species of the Poeae tribe. Each gene is represented by a uniquely colored arrow, indicating the direction of the coding sequence. Markers (37600, BAC_BEG, dark green) selected from the fine-mapping are displayed as uniquely colored rectangles and represent the flanking markers of the $Z$ locus region.

\section{References}

[1] Manzanares, C., Barth, S., Thorogood, D., Byrne, S. L., Yates, S, Czaban, A., Asp, T., Yang, B., Studer, B. (2016): A gene encoding a DUF247 domain protein co-segregates with the $S$ self-incompatibility locus in perennial ryegrass. Mol Biol Evol 33(4), 870-884 (2016)

[2] Byrne, S. L., Nagy, I., Pfeifer, M., Armstead, I., Swain, S., Studer, B., Mayer K., Campbell J. D., Czaban A., Hentrup S., Panitz F., Bendixen C., Hedegaard J., Caccamo M., Asp, T. (2015): A syntenybased draft genome sequence of the forage grass Lolium perenne. Plant J. 84(4), 816-826

[3] Frei, D., Veekman, E., Grogg, D., Stoffel-Studer, I., Morishima, A., Shimizu-Inatsugi, R., Yates, S., Shimizu, K. K., FreY, J. E., Studer, B., CopettI, D.: Ultralong Oxford Nanopore reads enable the development of a reference-grade perennial ryegrass genome assembly. Genome Biol Evol, in press 
[4] Copetti, D., Yates, S., Vogt, M. M., Russo, G., Grieder, C., Kölliker, R., Studer, B. (2021): Evidence for high intergenic sequence variation in heterozygous Italian ryegrass (Lolium multiflorum Lam.) genome revealed by a high-quality draft diploid genome assembly. bioRxiv

[5] Huang, L., Feng, G., Yan, H., Zhang, Z., Bushman, B. S., Wang, J., Bombarely A., Wang, J., Bombarely A., LI M., YANG Z., Nie G., XIE W., Xu L., Chen P., Zhao X., JiAng W., Zhang X. (2020): Genome assembly provides insights into the genome evolution and flowering regulation of orchardgrass. Plant Biotechnol J 18(2), 373-388

[6] VeltRI, D., Wight, M. M., CROUCH, J. A.: SimpleSYNTENy (2016): a web-based tool for visualization of microsynteny across multiple species. Nucleic Acids Res 44(W1), W41-W45 